\title{
A Model for Calculating the Spatial Coverage of Audible Disaster Warnings Using GTFS Realtime Data
}

\author{
Akihiko Nishino*D, Akira Kodaka, Madoka Nakajima and Naohiko Kohtake
}

Graduate School of System Design and Management, Keio University, Yokohama 223-8526, Kanagawa, Japan; akira.kodaka@sdm.keio.ac.jp (A.K.); madoka.nakajima@sdm.keio.ac.jp (M.N.); kohtake@sdm.keio.ac.jp (N.K.)

* Correspondence: akihiko.nishino@keio.jp; Tel.: +81-45-564-2518

Citation: Nishino, A.; Kodaka, A.; Nakajima, M.; Kohtake, N. A Model for Calculating the Spatial Coverage of Audible Disaster Warnings Using GTFS Realtime Data. Sustainability 2021, 13, 13471.

https://doi.org/10.3390/su132313471

Academic Editor: Hatim Sharif

Received: 26 October 2021

Accepted: 2 December 2021

Published: 6 December 2021

Publisher's Note: MDPI stays neutral with regard to jurisdictional claims in published maps and institutional affiliations.

Copyright: (c) 2021 by the authors. Licensee MDPI, Basel, Switzerland. This article is an open access article distributed under the terms and conditions of the Creative Commons Attribution (CC BY) license (https:/ / creativecommons.org/licenses/by/ $4.0 /)$.

\begin{abstract}
In the event of a large-scale disaster, the dissemination of audible disaster warning information via sirens is effective in ensuring a rapid response. Sirens can be installed not only on fixed towers, but also on public transport and other vehicles passing through residential areas, and at spots where residents congregate, to increase area coverage. Although models to calculate the spatial coverage of audible information delivered from fixed sirens have been constructed, no general-purpose model has been developed to assess the delivery from vehicles. In this study, we focused on the General Transit Feed Specification (GTFS), which is an open format for geospatial information on public transport. We conducted a spatial analysis using a geographic information system (GIS) on the basis of the acquired bus location information. We developed a model to calculate the spatial coverage of the audible information delivery for overlapping hazard maps and population. Assuming a flood occurred in the vicinity of Brisbane Central Station, Queensland, Australia, we confirmed that the developed model was capable of characterizing the time-series changes in the exposed population in the target area. Since the GTFS format is currently distributed across various countries, this assessment model is considered to be highly versatile and widely applicable.
\end{abstract}

Keywords: disaster information; warning dissemination; spatial coverage rate; GTFS; GIS

\section{Introduction}

The importance of early warning systems in the event of a major disaster is increasing worldwide. For example, the need to improve the accessibility of early warning systems and disaster warning information is mentioned in the Sendai Framework for Disaster Reduction 2015-2030 developed by the United Nations in Sendai, Japan. This framework defines specific indicators such as the number of people per 100,000 head of population that should be covered by early warning information [1]. However, in countries that are vulnerable to disasters, the capacity of early warning systems is often low [2]. Therefore, countries with a high-disaster-risk but a low early warning system capacity need an approach that allows them to improve the system quickly and easily [3]. There is also a need to properly assess the resilience and coverage of the information delivery [4].

Sirens are an effective means of early warning that have already been introduced in many countries and regions and are easily available as a resource. Sounding sirens, loudspeakers, and other broadcasting equipment to convey audio information are important as triggers to initiate evacuation and disaster response actions [5]. Although it is difficult to send out a large amount of information using these means, they are useful in that they can reach a large number of people in a short period of time [6]. Not only artificial sounds, but also natural sounds are effective in attracting people's attention. Hong et al. (2021) found that birdsongs can be a potential soundscape driver [7]. It is essential to assess the spatial coverage rate or the extent to which the audio information covers the area. Cao et al. [8] showed the effectiveness of the maximum value method in calculating the coverage ratio. In the maximum value method, when there are multiple methods 
of information transmission in the target area, the value of the method with the largest coverage ratio is adopted. In this process, the extent of information transmission needs to be visualized on the basis of the data. Eric [9] compared multiple methods of storm warning dissemination in Alabama, USA, by plotting the locations of sirens and cell phone base stations on a map using a geographic information system (GIS) and visualizing the information transmission area as a circular buffer of a certain radius. Adam et al. [10] used a GIS to build an evaluation model of the sound transmission of tornado warnings delivered from sirens and determined coverage rates of up to $97 \%$ of the population in Oklahoma, USA. To convey audio information to a large number of people more widely and quickly, both sirens installed on fixed radio towers and sirens attached to moving vehicles can be used. Through simulations, Kanai et al. [11] found that the speed of information transmission was faster with a "PR vehicle" than with sirens alone. After a disaster occurs, PR vehicles must be rapidly dispatched by local government agencies to the disaster area. The travel period can be long and, depending on the disaster situation, vehicles may not be able to reach their destination owing to road disruptions [12].

Nishino et al. [13] proposed a system in which sirens would be installed on public transport vehicles that run on a daily basis, such as buses and cabs. In the event of a disaster, vehicles that have stopped moving will sound their sirens urgently on the spot to transmit information immediately to as many people as possible. To assess the spatial coverage of this system, data on the location of every public transport vehicle that operates on a daily basis needs to be obtained. An example of valid data is probe data, which records the date and time of data acquisition, location information acquired by a global positioning system, and travel speeds, using unique identification numbers associated with each vehicle. Although probe data have been used to manage the dynamics of public transport during disasters [14], a suitable open format for public transport location information has not yet been applied to disaster information dissemination systems. The General Transit Feed Specification (GTFS) is a widely applied open format for storing the location information of public transport systems such as buses and trains [15]. The GTFS was developed by Google to increase the availability of public transport information. It is an open-source transport data format that is currently used all over the world. GTFS data includes static data and real-time data. Static GTFS data includes schedules and geographic information on routes and stops, while real-time GTFS data contains location information that is updated in real time according to the operational status of each bus. Therefore, by using GTFS Realtime data, it is possible to obtain the location information of public transport vehicles around the world where the data is available and to calculate the spatial coverage rate of disaster information dissemination. This approach can help each country to assess and implement their warning distribution systems.

In this study, we developed a model to calculate the spatial coverage of audio information broadcast from speakers installed in public transport vehicles immediately after a large-scale disaster using data distributed in the GTFS Realtime format. Applying this model to a flood scenario in Brisbane, Queensland, Australia, we confirmed that the effectiveness of voice information dissemination from public transport vehicles in a target area can be assessed using the temporal changes in the spatial coverage as each vehicle operates.

This study focused on floods as a type of disaster. In recent years, the damage caused by floods has become so severe that flood early warning systems are being considered in many parts of the world [16]. Flood early warning systems aim to provide immediate warnings to vulnerable populations without delay and with sufficient lead time to enable response actions [17]. However, they focus only on hazard prediction and do not consider the exposure of the target area, including buildings and people [18]. In particular, there is a need for people in high-risk areas to have rapid access to appropriate information through multiple means [19]. There are several processes involved in flood warning systems, ranging from "knowledge of risk" to "response capacity" [20], with an emphasis on "dissemination and communication" in terms of people getting the information they 
need to save their lives. Spatial information is necessary for flood risk assessment [21], and in this study, spatial coverage was used as an evaluation index to assess the risk of flooding.

\section{Materials and Methods}

Australia is one of the main countries threatened by floods, especially in Brisbane, Australia's third largest city, which has experienced frequent flood disasters over time. A recent example occurred in January 2011, when heavy rains caused the Brisbane River to overflow, affecting approximately 29,000 homes and businesses and 2.5 million people [22]. The 2011 floods highlighted the need for an adequate warning dissemination system in Brisbane [23]. During these floods, information was mainly gathered through television, radio, and the internet [24], but the need for broadcasting at the local level is apparent [25]. The effectiveness of using sirens for flood warning dissemination has been identified [26], and the installation of sirens is being considered in the Brisbane area [27]. Currently, GTFS data is available in Brisbane and has been used to study the dynamics of public transport [28]. On this basis, we assumed that sirens could be installed on public buses to deliver audible flood disaster information in Brisbane.

The model for calculating the spatial coverage is shown in Figure 1. The novelty of this model lies in its ability to compute dynamic time-series changes in the spatial coverage using GTFS Realtime data, which is a highly accessible and widely used data format compared to that used in previous methods [9,10]. The model consists of two steps: (1) data acquisition, and (2) coverage rate calculation. ArcGIS software (Esri, Redlands, CA, USA) was adopted for the calculation model because of its versatility.

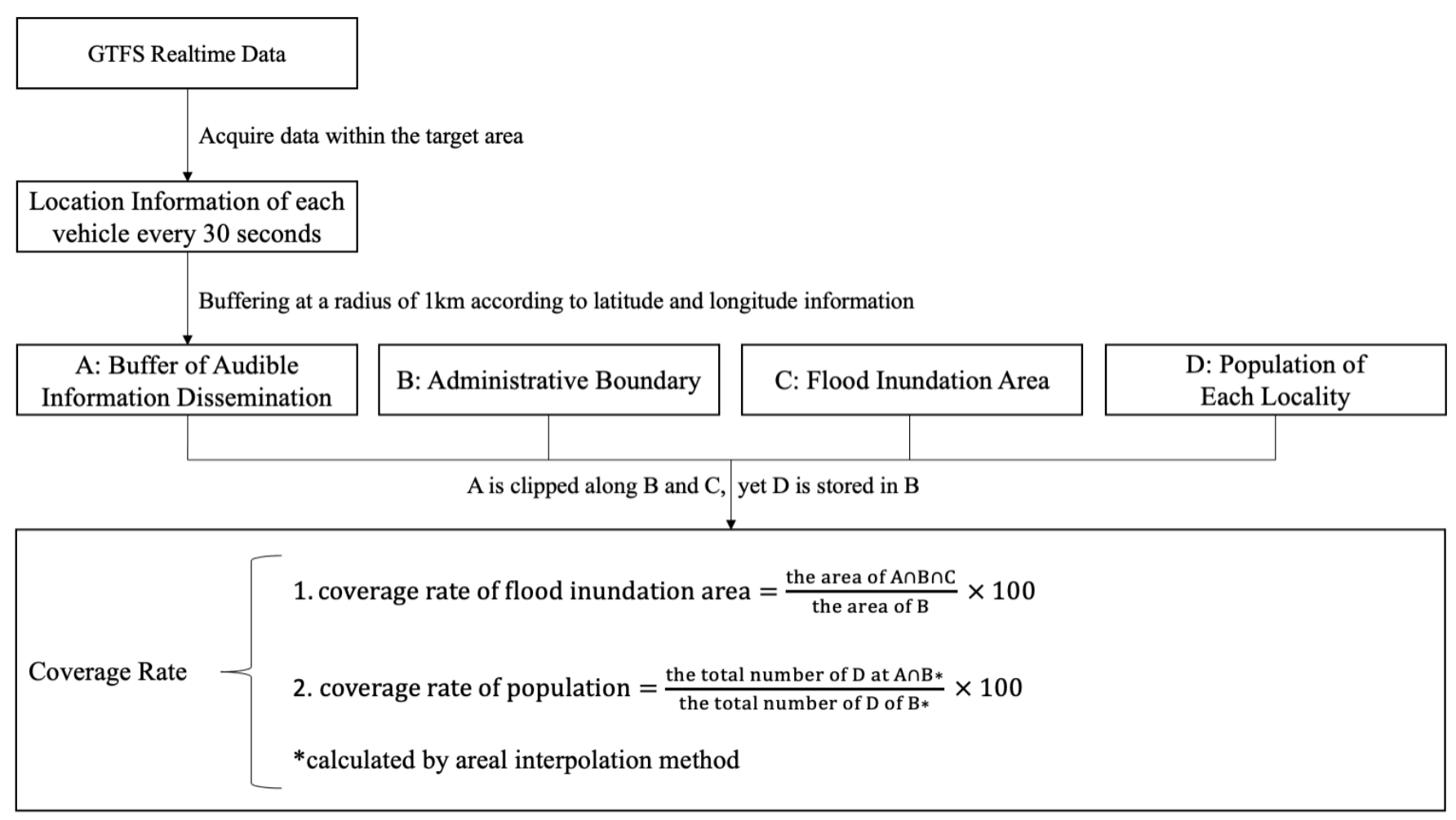

Figure 1. Spatial coverage rate calculation model.

\subsection{Data Acquisition}

To retrieve the GTFS data, we used ArcGIS GeoEvent Server. This is a component of ArcGIS that provides a connection to real-time data. First, we built the server and configured it to receive the GTFS Realtime feed. Next, we built a geoevent service consisting of an input connector, a filtering component, and an output connector. The input connector 
was connected to the GTFS Realtime feed that is available on the Translink website, which is used for public transport in Brisbane [29]. For the filtering, the range of vertices of the minimum bounding short form containing the target region was specified in terms of latitude and longitude. In this case, the target area was within a radius of $10 \mathrm{~km}$ from Brisbane Central Station, which includes the central business district. The target period for data acquisition was Sunday, 27 December 2020. This date was chosen to understand the pattern of bus travel on holidays. We specified the CSV format as the output connector and started the GeoEvent Server during the target period. Real-time data from the GTFS, which was transmitted every $30 \mathrm{~s}$, was acquired during the target period as a CSV file, the name of which corresponded to the hour, minute, and second of the transmission time. Each file contained the latitude and longitude information of all the buses active within the time range indicated by the file name.

\subsection{Spatial Coverage Rate Calculation}

To calculate the spatial coverage on the basis of the acquired data, ArcGIS Pro, a desktop application of ArcGIS capable of spatial analysis, was used. Two indicators of spatial coverage were selected: the percentage of the population reached in the inundation area in the 2011 flood [30] and the percentage of the population reached in each region in 2019 [31]. First, a point layer was created from the latitude and longitude information in the CSV file. Next, a layer was created around each point incorporating a buffer with a radius of $1 \mathrm{~km}$, which corresponded to the reach of a typical siren manufactured by Whelen Engineering Company (Chester, CT, USA). The coverage of a siren is related to the power of a siren [32], and the sound pressure of the siren is $70 \mathrm{~dB}$. To calculate the percentage of the flood inundation area reached, the buffer layer was clipped using the flood inundation area boundary data. The area of the buffer layer was calculated as a percentage of the area of the boundary data on the basis of the area values stored in the attribute table of the clipped buffer layer and boundary data. To calculate the percentage of population reached, the ratio of the total population in the buffer to the total population in the target area was calculated using the areal complement method [33]. The results of the calculation were then written to an XLS file, Microsoft Excel file format, retaining the file naming conventions. The model was run on ArcGIS Pro for all CSV files, repeating the above process. Each XLS file was marked with the transmission time and spatial coverage rate. All the XLS files were then integrated using the macro function of Microsoft Excel to visualize the time-series changes as a graph. The maximum and minimum spatial coverage rates calculated every $30 \mathrm{~s}$ during the target period were identified and visualized on a map in ArcGIS Pro.

This time, instead of the location information assumed based on the timetable, realtime location information was obtained, taking into account the relationship between the bus drivers. If the target vehicle were an emergency vehicle and the voice information were sent to the driver of a regular vehicle, the driver would be an important factor [34], but in this case, the driver was not an important factor in the model because the voice information was sent not only to the bus driver and passengers, but also to people around the vehicle. Therefore, the drivers' relationship was not an important factor in this model.

The model was validated by conducting an experiment in which all bus vehicles in Brisbane were actually equipped with speakers and driven to measure the reach of audible information delivery, but it could also be confirmed in the following three aspects: (1) The GTFS Realtime data in Brisbane is correctly updated [28]; (2) ArcGIS GeoEvent Server can correctly acquire the data that is updated in real time [35]; and (3) ArcGIS can correctly visualize the reach of the audible information as a buffer layer $[9,10]$.

\section{Results}

\subsection{Visualization of Information Dissemination}

Figure 2 shows the maximum spatial coverage of audible information delivered by bus over the flood inundation area. The large black circle indicates the target area, i.e., the area within a $10 \mathrm{~km}$ radius around Brisbane Central Station. The inundation area of the major 
flood that occurred in 2011 is shown in blue. Population density is shown in a color scale, with darker red indicating higher population density. The hatched buffers indicate a radius of $1 \mathrm{~km}$ of audible information delivery centered on a bus. The spatial coverage for the population reached a maximum value of $87.91 \%$ at 16:48:49 (shown in Figure 2). In contrast, the minimum value of $31.04 \%$ was reached at $1: 47: 47$, which is close to midnight. The spatial coverage of the flooded area showed the maximum value of $74.68 \%$ at $15: 42: 49$, while the minimum value of $20.95 \%$ was observed at 1:47:47 midnight, which was similar to the coverage of the population.

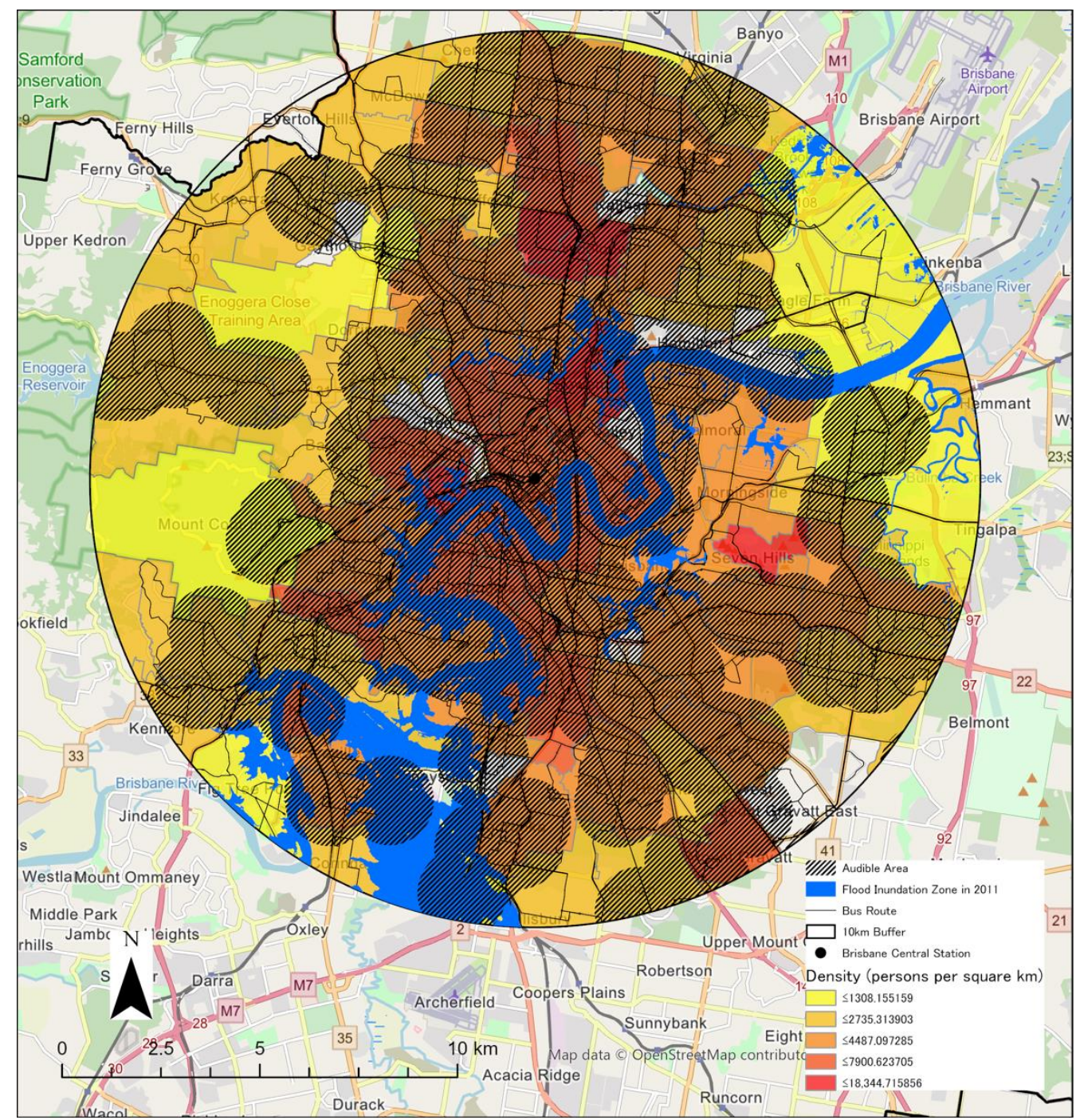

Figure 2. The reach of audible information when buses within a $10 \mathrm{~km}$ radius of Brisbane Central Station sounded their sirens on a holiday. The reach is shown at 16:48:49 when the spatial coverage of the population was $87.91 \%$ of the total population.

\subsection{Time-Series Change in Spatial Coverage Rate}

Figure 3 shows the time-series spatial coverage of the flood inundation area during the period of interest. The vertical axis is the coverage (\%) and the horizontal axis is the time (hours, minutes, and seconds). The data is plotted at intervals of approximately $30 \mathrm{~min}$ because the $30 \mathrm{~s}$ intervals of the GTFS data cannot be properly displayed at this scale. The scale on the horizontal axis varies because there were fewer buses running early in the morning and late at night. The time-series spatial coverage of the flood inundation area is plotted by the solid line. The results show that approximately $60 \%$ of the flood inundation area could be reached at all times during the holidays. During the study period, the spatial 
coverage ratio increased from early morning, peaked in the evening, and fell during the night. There were repeated fluctuations during the day.

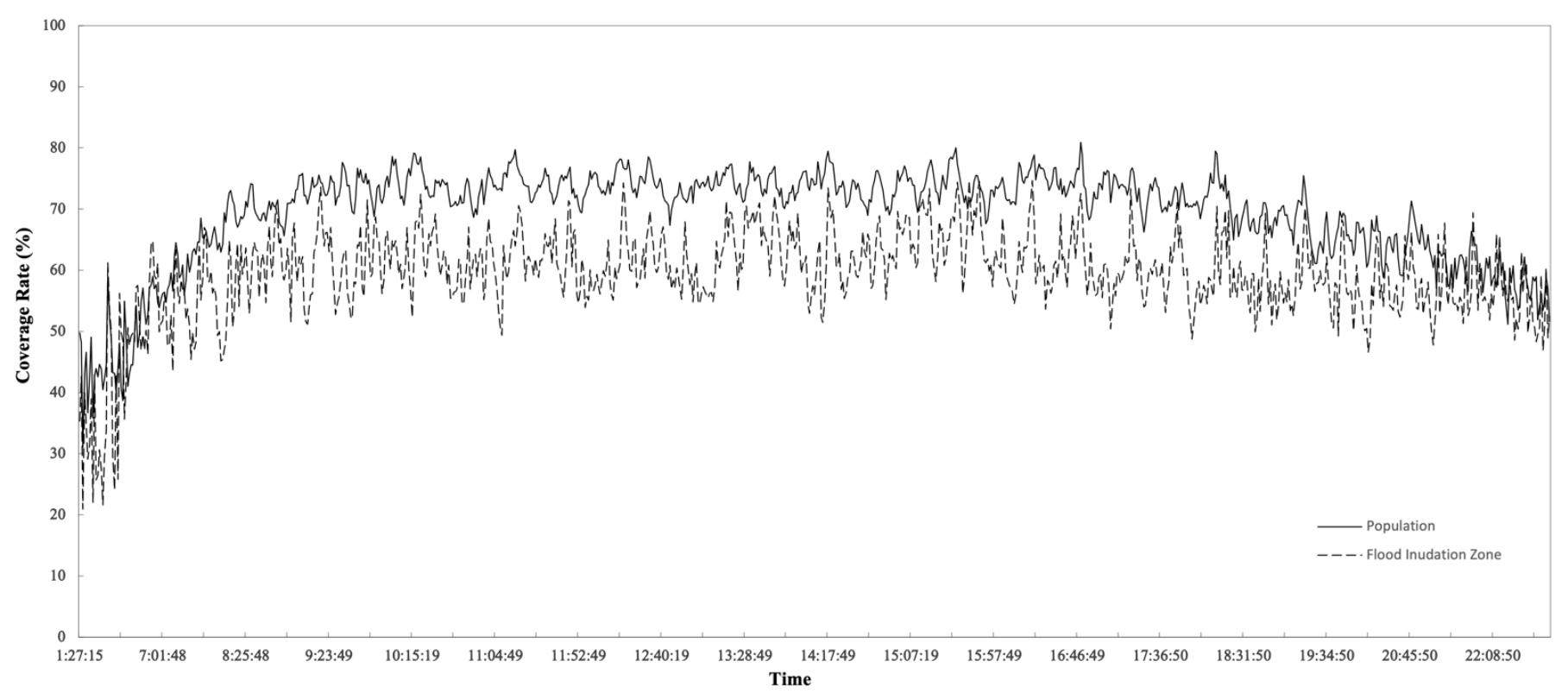

Figure 3. Time-series change in the spatial coverage rate of the population and flood inundation area.

The time-series spatial coverage of the population is shown by the dotted line in Figure 3 . The results indicate that approximately $70 \%$ of the population could be contacted continuously during holidays. It can also be seen that the spatial coverage by population is much less variable than the spatial exceedance rate of the flood inundation area.

To find the difference between the spatial coverage of the population and the spatial coverage of the flood, we simply subtracted the latter from the former and set the value of 8:47:48 (0.129) — which had the smallest difference- to 1 , as shown in the equation below:

Difference $=\frac{(\text { spatial coverage rate of population })-(\text { spatial coverage rate of flood inundation area })}{\text { the minimum value of numerator }}$

The largest positive difference was at 10:15:19, with a value of 196.73. The largest negative difference was at 6:20:47 with a value of -78.58 .

\section{Discussion}

\subsection{Effectiveness of the Model}

In the case of Brisbane, we found that the delivery of audible information via sirens attached to buses could reach approximately $60 \%$ of the flood inundation area at any given time during a holiday. It was also found that approximately $70 \%$ of the population in the target area could be reached. Therefore, the model of spatial coverage of audible information dissemination using GTFS data was an effective way to measure the delivery of information to the population in the target area. The objective of this study-the development and evaluation of the model-was accomplished on the basis of two types of coverage. The inner city of Brisbane has a large population during the day, and it is expected that information disseminated from buses running during the day will reach a large number of people.

According to the time-series change in the spatial coverage rate, the coverage rate tended to peak in the evening, but disaster information could also be distributed early in the morning or late at night when the spatial coverage rate was low. This allows for effective disaster management planning in the target area. Table 1 shows a possible timeline for the major flood event in Brisbane. The sequence of events is based on the major 
flood that occurred in 2011 [22], and the italicized text indicates when audio information would be effectively delivered from sirens mounted on buses. If the Brisbane River started to overflow at night, the warning could be distributed from buses running early in the morning or late at night to warn the citizens as soon as possible. However, if the evacuation were to begin the next day when there were no traffic restrictions, evacuation orders could be broadcast from buses in the evening when spatial coverage is high, so that the evacuation could be completed before the flood peak. This shows that the present model can contribute to more effective planning and evaluation of flood warning dissemination in Brisbane. This model needs to be tested in other hazard scenarios in different regions to assess the response to non-flood hazards.

Table 1. Effective timeline of flood management in Brisbane.

\begin{tabular}{cc}
\hline & 10 January \\
\hline $0: 00$ & Overflow \\
\hline & Alert via sirens attached to public transport vehicles \\
\hline Morning & Evacuation Advisory in the central business district (No Traffic Regulations) \\
\hline Daytime & Flooding begins in the city \\
\hline Afternoon & Evacuation starts \\
\hline Evation order via sirens attached to public transport vehicles \\
\hline Afternoon & 12 January \\
\hline 2:30 & Blackout in the central business district \\
\hline Daytime & Prime Minister calls for suspension of business and voluntary restraint \\
\hline & 13 January \\
\hline- & Vigilance by rescue vehicles and ships \\
\hline & 14 January \\
\hline & Water level drops / flooding continues
\end{tabular}

By combining the spatial coverage and time-series changes in Figures 3 and 4, it was possible to identify the locations in the target area where audible information could be delivered at all times and where it could not be delivered at all. In the scenario shown in Table 1, if the flood lead time is long enough, the coverage can be reduced while buses change their normal travel routes to locations where audible information cannot be delivered. The results of this study will be useful for this kind of flexible planning. Figure 4 also allowed us to examine the exposure of the target area according to the time of day, on the basis of Equation (1), which shows the difference between the spatial coverage of the population and the spatial coverage of the flood inundation area. For example, at 10:15:19, most of the population was covered, but the flood inundation area was not well covered, and priority would best be given to those people who may be in the uncovered inundation area. Most of the inundation area was covered at $6: 20: 47$, but the population coverage was not sufficient; therefore, it would be important to provide appropriate information to a large number of people in the non-inundated areas. By comparing the difference in the spatial coverage rate between the two types, it is possible to better plan the response to disseminate information to the population exposure. 


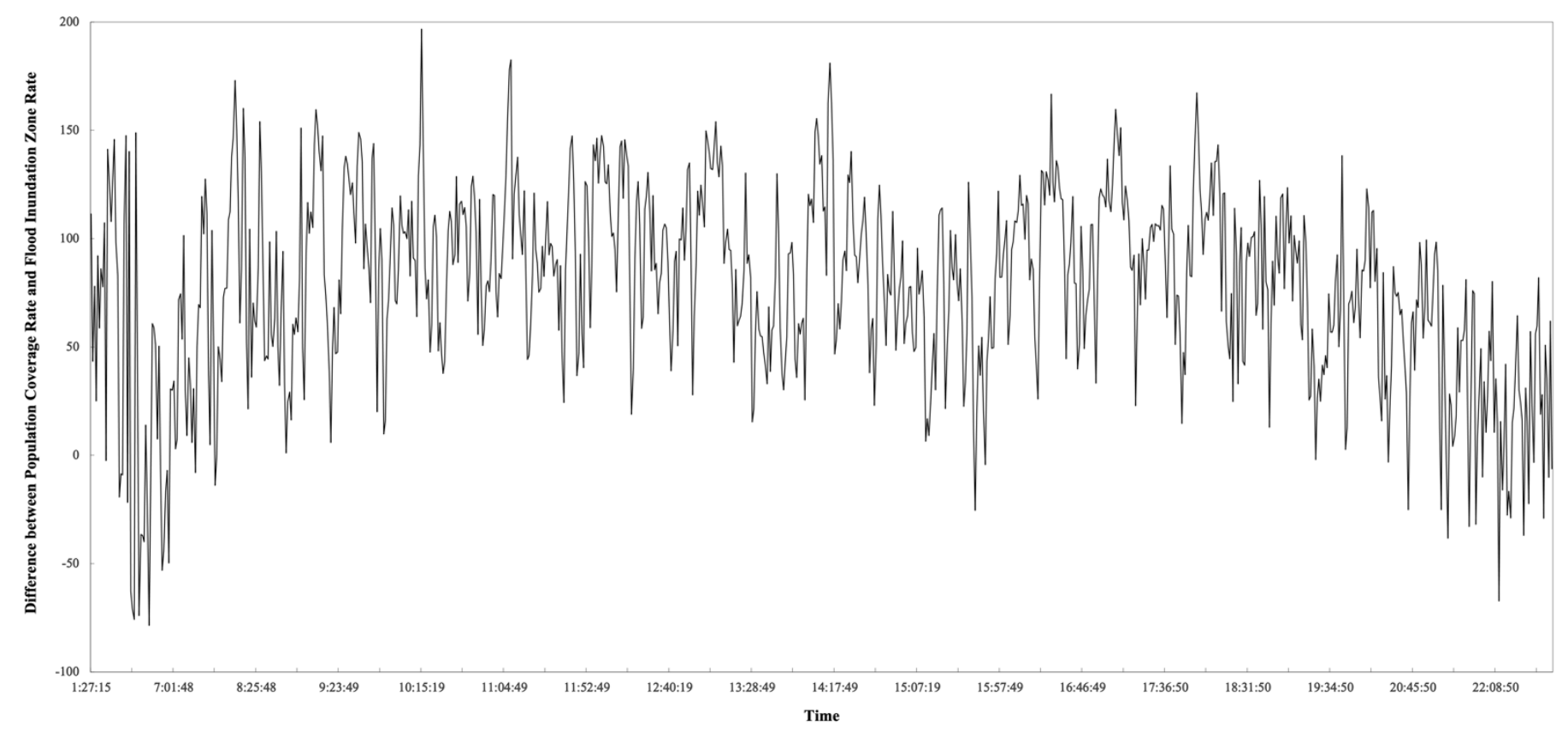

Figure 4. Time-series change of the spatial coverage rate of the population minus the spatial coverage rate of the flood inundation area; the ratio when the value was at 8:47:48, which had the smallest difference, was set to 1.

To calculate the spatial coverage and assess the effectiveness of the system, we needed real-time data from the GTFS, which represents the location of the public transport system. GTFS data are available not only in Brisbane but also all over the world. Currently, more than 1300 transportation agencies around the world share the static data of the GTFS, and more than 200 agencies share the real-time data of the GTFS, including data on buses and trains [36]. Therefore, the model can be applied to other disaster-prone regions. In many disaster-prone regions in Asia and Oceania, warning communication systems have not been introduced as a nationwide public service. The use of public transport systems such as buses and trains are feasible and can be assessed on the basis of GTFS data. Our approach would support the introduction of warning dissemination systems in other Asian and Oceanian regions.

Each process of computational modeling was performed using widely available and versatile tools such as ArcGIS. This is expected to reduce the specialization of the modeling and simulation processes and make it easier for government disaster management officials who are considering how to improve and assess the spatial coverage of disaster warning information. The importance of selecting the right tool to be used for assessing the effectiveness of disaster management implementation has been highlighted [37]. The need to build a flood warning system that can easily be accessed and understood by local stakeholders has also been identified [38]. In the future, we aim to package and implement this model and provide it to local stakeholders in high-disaster-risk areas where GTFS data is available to support the implementation of warning distribution systems.

\subsection{Limitation of the Study}

The model needs to be assessed with reference to the specific behaviors and characteristics of people who are outdoors at different times of the day. It will also be necessary to consider the dissemination of disaster information to people who are indoors. Factors such as land cover, buildings, trees, and wind also need to be considered when simulating the sound disseminated from an actual siren [10]. The complexity of the simulation model has been discussed before [32], and it was found to be difficult to simplify the computational model. Another concern is congestion in the audible information delivery owing to overlapping buffers. The impact of the sound pressure of a siren on congestion or spatial coverage should also be considered. In our previous work, we simulated the optimal siren 
placement considering the overlapping range of buffers [39]. As a next step, we would like to calculate the spatial coverage rate in real time, considering the distance between vehicles.

\section{Conclusions}

In this study, we developed a model to calculate the spatial coverage of audio information delivered from sirens installed on public transport systems during disasters by obtaining GTFS data of the location of the buses delivering the information. The location information on the buses was obtained in GTFS Realtime format, and the coverage of the delivered information was calculated on the basis of the flood inundation area and population using GIS tools. Applying this model to a flood scenario in Brisbane, we found that in the city center the delivery of audio messages from the buses would reach $60 \%$ of the flood inundation area and $70 \%$ of the population at any given time. We confirmed that our model can assess the dissemination of voice information from public transport vehicles by calculating the time-series change in the exposed population when voice information is delivered from buses. This model can contribute to risk assessment in many regions because it uses open format GTFS data that is distributed worldwide. In the future, we plan to test the effectiveness of this model on the basis of different hazard and regional scenarios.

Author Contributions: Conceptualization, A.N. and M.N.; data curation, A.N.; formal analysis A.N.; funding acquisition, A.K. and N.K.; investigation, A.N. and A.K.; methodology, A.N. and M.N.; project administration, A.K. and N.K.; resources, N.K.; Software, A.N.; supervision, N.K.; visualization, A.N., A.K. and M.N.; writing-original draft preparation, A.N.; writing-review and editing, A.K., M.N. and N.K. All authors have read and agreed to the published version of the manuscript.

Funding: This research was funded by JST Belmont Forum, grant number JPMJBF2004.

Institutional Review Board Statement: Not applicable.

Informed Consent Statement: Not applicable.

Data Availability Statement: Not applicable.

Conflicts of Interest: The authors declare no conflict of interest.

\section{References}

1. Sendai Framework Indicators. Available online: https://www.preventionweb.net/sendai-framework/sendai-frameworkmonitor/indicators (accessed on 25 October 2021).

2. Lima-Paris Action Agenda. Available online: http://newsroom.unfccc.int/lpaa/resilience/climate-risk-and-early-warningsystems-initiative-strengthening-the-systems-at-the-heart-of-resilience/ (accessed on 25 October 2021).

3. Haigh, R.; Amaratunga, D.; Hemachandra, K. A capacity analysis framework for multi-hazard early warning in coastal communities. Procedia Eng. 2018, 212, 1139-1146. [CrossRef]

4. Aguirre, A.I.; Merino, M.; Aye, S.L.; Dissanayake, R.; Shadiya, F.; Lopez, C.M. An evaluation of availability and adequacy of Multi-Hazard Early Warning Systems in Asian countries: A baseline study. Int. J. Disaster Risk Reduct. 2020, 49, 101749. [CrossRef]

5. Bopp, E.; Douvinet, J. Spatial performance of location-based alerts in France. Int. J. Disaster Risk Reduct. 2020, 50, 101909. [CrossRef]

6. Sillem, S. Warning Citizens Influencing Self-Reliance in Emergencies. Ph.D. Thesis, Delft University of Technology, Delft, The Netherlands, 2010.

7. Hong, X.-C.; Wang, G.-Y.; Liu, J.; Song, L.; Wu, E.T.Y. Modeling the impact of soundscape drivers on perceived birdsongs in urban forests. J. Clean. Prod. 2021, 292, 125315. [CrossRef]

8. Cao, Z.; Feng, Y.; Li, X. A Study on the Calculation Method for the Coverage Rate of Early Warning Release. IOP Conf. Ser. Earth Environ. Sci. 2019, 233, 052034. [CrossRef]

9. Best, E. Development of Hybrid Notification Systems for Use in Storm-Based Warnings in Rural Communities. Nat. Hazards Rev. 2017, 18, 05017001. [CrossRef]

10. Mathews, A.J.; Haffner, M.; Ellis, E.A. GIS-based modeling of tornado siren sound propagation: Refining spatial extent and coverage estimations. Int. J. Disaster Risk Reduct. 2017, 23, 36-44. [CrossRef]

11. Kanai, M.; Hosoi, K.; Katada, T. Development of Tool for the Community Strategy to Communicate Disaster Information for Disasters Attacking Local Area. J. Disaster Inf. Stud. 2010, 8, 120-130.

12. Kameda, K. Consideration of Sociological Approach on Disaster Information Transmission and Evacuation Activity -Based on case study of Tarumizu City. J. Disaster Inf. Stud. 2010, 8, 75-85. 
13. Nishino, A.; Nakajima, M.; Kohtake, N. GNSS-based M2M early warning system for the improved reach of information. In Proceedings of the 2016 IEEE Aerospace Conference, Big Sky, MT, USA, 5-12 March 2016; pp. 1-8.

14. Hada, Y.; Suzuki, T.; Shimora, H.; Megro, K.; Kodama, N. Issues and Future Prospect on Practical Use of Probe Vehicle Data for Disaster Reduction-Provision of the Vehicle Tracking Map in the 2007 Niigataken Chuetsu-oki Earthquake. J. Jpn. Assoc. Earthq. Eng. 2009, 9.2, 148-159. [CrossRef]

15. Bok, J.; Kwon, Y. Comparable measures of accessibility to public transport using the general transit feed specification. Sustainability 2016, 8, 224. [CrossRef]

16. Flood Hazard and Risk Assessment, UNISDR. Available online: https://www.undrr.org/publication/flood-hazard-and-riskassessment (accessed on 25 October 2021).

17. Tarchiani, V.; Massazza, G.; Rosso, M.; Tiepolo, M.; Pezzoli, A.; Housseini Ibrahim, M.; Rapisardi, E.; Katiellou, G.L.; Tamagnone, P.; De Filippis, T.; et al. Community and impact based early warning system for flood risk preparedness: The experience of the Sirba River in Niger. Sustainability 2020, 12, 1802. [CrossRef]

18. Fakhruddin, S.H.M.; Kawasaki, A.; Babel, M.S. Community responses to flood early warning system: Case study in Kaijuri Union, Bangladesh. Int. J. Disaster Risk Reduct. 2015, 14, 323-331. [CrossRef]

19. Prathumchai, K.; Bhula-or, R. Understanding Households' Perceptions of Risk Communication during a Natural Disaster: A Case Study of the 2011 Flood in Thailand. J. Disaster Res. 2020, 15, 621-631. [CrossRef]

20. Miyamoto, M.; Osti, R.; Okazumi, T. Development of an integrated decision-making method for effective flood early warning system. J. Disaster Res. 2014, 9, 55-68. [CrossRef]

21. Foudi, S.; Osés-Eraso, N.; Tamayo, I. Integrated spatial flood risk assessment: The case of Zaragoza. Land Use Policy 2015, 42, 278-292. [CrossRef]

22. Queensland Floods Commission of Inquiry Final Report. Available online: http://www.floodcommission.qld.gov.au/_data/ assets/pdf_file/0007/11698/QFCI-Final-Report-March-2012.pdf (accessed on 25 October 2021).

23. Van den Honert, R.C.; McAneney, J. The 2011 Brisbane floods: Causes, impacts and implications. Water 2011, 3, 1149-1173. [CrossRef]

24. Zheng, Z.; Lee, J.B.; Saifuzzaman, M.; Sun, J. Exploring association between perceived importance of travel/traffic information and travel behaviour in natural disasters: A case study of the 2011 Brisbane floods. Transp. Res. Part C: Emerg. Technol. 2015, 51, 243-259. [CrossRef]

25. Kammerbauer, M.; Minnery, J. Risk communication and risk perception: Lessons from the 2011 floods in Brisbane. Aust. Disasters 2019, 43, 110-134. [CrossRef]

26. Bajracharya, S.R.; Khanal, N.R.; Nepal, P.; Rai, S.K.; Ghimire, P.K.; Pradhan, N.S. Community Assessment of Flood Risks and Early Warning System in Ratu Watershed, Koshi Basin, Nepal. Sustainability 2021, 13, 3577. [CrossRef]

27. WPS2906 Six Cell Mass Notification Warnign Product, Whelen Engineering Company, Inc. Available online: https://www. whelen-engineering.com/pb/Mass\%20Notification/Product\%20Sheets/WPS2906.pdf (accessed on 25 October 2021).

28. Lim, A.; Sharma, S.; Bhaskar, A.; Arkatkar, S. An open source framework for GTFS data analytics: Case study using the Brisbane TransLink network. In Proceedings of the 41st Australasian Transport Research Forum (ATRF), Canberra, Australia, 30 September-2 October 2019.

29. Tranlink GTFS Real-Time Feed. Available online: https://gtfsrt.api.translink.com.au (accessed on 25 October 2021).

30. Flood Extent-Queensland-January 2011, Queensland Spatial Catalogue. Available online: http:/ / qldspatial.information.qld.gov. au/catalogue/custom/detail.page?fid= \\{C3F4BC07-88B3-410C-904B-957933079AA8 $\}$ (accessed on 25 October 2021).

31. Population Estimates Regions, Queensland Government Statistician's Office. Available online: https://www.qgso.qld.gov. $\mathrm{au} /$ statistics/theme/population/population-estimates/regions\#current-release-estimated-resident-population (accessed on 25 October 2021).

32. Rosas-Bermejo, E.N.; Rafael-Valdivia, G.; Paucar-Curasma, R. Analysis of Sound Propagation for Outdoor Emergency Speakers Networks. In Proceedings of the 2016 IEEE ANDESCON, Arequipa, Peru, 19-21 October 2016.

33. Holt, J.B.; Lo, C.P.; Hodler, T.W. Dasymetric estimation of population density and areal interpolation of census data. Cartogr. Geogr. Inf. Sci. 2004, 31, 103-121. [CrossRef]

34. Moore, D.; Boslem, S.; Charissis, V. Optimisation of Sound Localisation for Emergency Vehicle Sirens through a Prototype Audio System, International Conference of Design, User Experience, and Usability; Springer: Berlin/Heidelberg, Germany, 2011.

35. Yao, F.; Wang, Y. Towards resilient and smart cities: A real-time urban analytical and geo-visual system for social media streaming data. Sustain. Cities Soc. 2020, 63, 102448. [CrossRef]

36. OpenMobilityData. Available online: http://transitfeeds.com (accessed on 25 October 2021).

37. Thompson, I.; Shrestha, M.; Chhetri, N.; Agusdinata, D.B. An institutional analysis of glacial floods and disaster risk management in the Nepal Himalaya. Int. J. Disaster Risk Reduct. 2020, 47, 101567. [CrossRef]

38. Wang, Z.; Yao, W.; Wang, M.; Xiao, P.; Yang, J.; Zhang, P.; Wu, J.; Tang, Q.; Kong, X. The Influence of River Channel Occupation on Urban Inundation and Sedimentation Induced by Floodwater in Mountainous Areas: A Case Study in the Loess Plateau, China. Sustainability 2019, 11, 761. [CrossRef]

39. Goto, H.; Murray, A.T. Acoustical properties in emergency warning siren coverage planning. Comput. Environ. Urban 2020, 81, 101477. [CrossRef] 